\title{
Macrophage pro-inflammatory cytokine secretion is enhanced following interaction with autologous platelets
}

\author{
Christopher M Scull, William D Hays, Thomas H Fischer
}

\begin{abstract}
Background: Macrophages are the dominant phagocyte at sites of wound healing and inflammation, and the cellular and acellular debris encountered by macrophages can have profound effects on their inflammatory profile. Following interaction with apoptotic cells, macrophages are known to switch to an anti-inflammatory phenotype. Activated platelets, however, are also a major component of inflammatory lesions and have been proposed to be pro-inflammatory mediators. In the present study, we tested the hypothesis that macrophage interaction with activated platelets results in an inflammatory response that differs from the response following phagocytosis of apoptotic cells.
\end{abstract}

Methods: Human monocyte-derived macrophages (hMDMs) were co-incubated with autologous activated platelets (AAPs) and the platelet-macrophage interaction was examined by electron microscopy and flow cytometry. The cytokines TNF- $\alpha, \mathrm{IL}-6$, and IL-23 were also measured during LPS-activated hMDM co-incubation with AAPs, which was compared to co-incubation with apoptotic lymphocytes. Cytokine secretion was also compared to platelets pre-treated with the gluococorticoid dexamethasone.

Results: Macrophages trapped and phagocytized AAPs utilizing a mechanism that was significantly inhibited by the scavenger receptor ligand fucoidan. LPS-induced macrophage secretion of TNF- $\alpha$, IL-6, and IL-23 was inhibited by co-incubation with apoptotic cells, but enhanced by co-incubation with AAPs. The platelet-dependent enhancement of LPS-induced cytokines could be reversed by pre-loading the platelets with the glucocorticoid dexamethasone.

Conclusions: The interaction of human macrophages with autologous platelets results in scavenger-receptormediated platelet uptake and enhancement of LPS-induced cytokines. Therefore, the presence of activated platelets at sites of inflammation may exacerbate pro-inflammatory macrophage activation. The possibility of reversing macrophage activation with dexamethasone-loaded platelets is a promising therapeutic approach to treating unresolved inflammation.

\section{Background}

A major function of macrophages is phagocytosis of cellular and acellular debris during inflammation and wound healing, and the activation response of macrophages following phagocytosis can be varied depending on the local extracellular environment [1-6]. The importance of phagocytosis in the resolution of inflammation is emphasized by pathological conditions involving

\footnotetext{
* Correspondence: cms2232@columbia.edu

Francis Owen Blood Research Lab, Department of Pathology and Laboratory Medicine, University of North Carolina at Chapel Hill, 125 University Lake Rd, Chapel Hill, NC 27516, USA
}

impaired phagocytosis, which may manifest as persistent infections or chronic inflammatory lesions such as diabetic ulcers and atherosclerotic plaques [7-11].

During their differentiation from primary monocytes, macrophages acquire specialized receptors and machinery for recognizing and clearing both apoptotic and infected cells [12]. In clearing apoptotic cells, macrophages use receptors such as scavenger receptors and integrins that function independently or in cooperation with each other depending on the type of cell targeted for phagocytosis [13-19]. 
Platelets are anucleate cells which play an integral role in maintaining vascular integrity. Within their 8-10 day lifespan, platelets can become activated either in the circulation or during adherence at a site of injury, and during this process they become targeted for destruction by macrophages [20]. The process of platelet activation involves several changes to the cell surface, including expression of P-selectin and loss of membrane asymmetry [21-23]. These changes in the platelet membrane may provide molecular signals to macrophages that trigger phagocytosis, although the precise mechanism by which macrophages recognize and phagocytose activated platelets remains to be identified.

Cells that have become apoptotic as part of their normal life cycle are recognized and cleared by phagocytosis in a manner that usually inhibits pro-inflammatory responses [24-27]. Although circulating platelets can exert a pro-inflammatory effect on circulating monocytes [28,29], their effect on differentiated macrophages, particularly at sites of inflammation, is not clear. We show here that phagocytosis of autologous platelets results in an pro-inflammatory profile that is opposite to the macrophage response following phagocytosis of apoptotic cells. Importantly, the platelet-enhanced, proinflammatory response of macrophages can be inhibited when the platelets are loaded with the glucocorticoid dexamethasone. In addition to novel insight into the macrophage inflammatory profile that exists in several diseases, these results also provide evidence that platelet-macrophage interactions are an important therapeutic target for reducing inflammation.

\section{Methods}

\section{Monocyte-derived Macrophages}

Human monocytes were isolated and cultured using techniques similar to those previously described [30,31]. Briefly, blood from healthy human donors was collected into citrate and peripheral blood mononuclear cells (PBMCs) were isolated by using Lymphoprep (Accurate Chemical) according to the manufacturer's instructions. Monocytes were further isolated by plating the PBMCs on gelatin-coated tissue culture flasks for $45 \mathrm{~min}$ at $37^{\circ} \mathrm{C}$ followed by 10 washes with phosphate buffered saline (PBS) to remove non-adherent lymphocytes. Monocytes were then detached from the flasks by incubation in 10 $\mathrm{mM}$ EDTA for $2 \mathrm{~min}$ at $37^{\circ} \mathrm{C}$. Monocytes (250,000 in 500 $\mu \mathrm{l}$ volume) were then plated in 24-well plates overnight in RPMI 1640 supplemented with $10 \%$ fetal bovine serum (FBS) and $10 \mathrm{ng} / \mathrm{ml}$ recombinant human GM-CSF (R\&D Systems). Monocytes were plated on glass coverslips for scanning electron microscopy (SEM) analysis and plastic tissue-culture plates for TEM analysis and phagocytosis experiments. Media was changed on day 2 and day 5 , and after 7 days of culture the MDMs were used for phagocytosis and cytokine assays.

\section{Platelets}

Platelets were isolated from whole blood collected into acid-citrate-dextrose (ACD) from healthy human donors and centrifuged for $15 \mathrm{~min}$ at $500 \times g$ to generate platelet-rich plasma (PRP). PRP was pelleted by centrifugation for $10 \mathrm{~min}$ at $800 \times g$ and the platelet pellet subsequently washed 2 times in citrated saline ( $\mathrm{pH}$ 6.8). A portion of the platelet samples were degranulated by incubating $1 \mathrm{ml}$ of platelets $(250,000 / \mu \mathrm{l}$ in citrated saline) with $10 \mu \mathrm{l}$ of $10 \mu \mathrm{M}$ calcium ionophore A21387 (Sigma) for $15 \mathrm{~min}$ with rocking at room temperature, followed by three centrifugational washes with citrated saline. For phagocytosis experiments, platelets were fluorescently labeled with Cell Tracker Green CMFDA (Invitrogen) as previously described [32]. After the final wash, and prior to use in phagocytosis assays, platelets were resuspended in warm serum-free RPMI for 15 min at $37^{\circ} \mathrm{C}$.

For analysis of surface P-selectin and phosphatidylserine, platelets $(250,000 / \mu \mathrm{l})$ were first incubated in either citrated saline or serum-free RMPI media for $1 \mathrm{hr}$ at $37^{\circ} \mathrm{C}$. A portion of the platelets were activated by including thrombin (King Pharmaceuticals, $1 \mathrm{U} / \mathrm{ml}$ final concentration) in the incubation reaction. To detect surface expression of activation markers in each platelet treatment group, a $10 \mu \mathrm{l}$ aliquot of platelets was stained with either FITC-antiCD62P (Biolegend) or FITC-Annexin-V (Biolegend) for $30 \mathrm{~min}$ at room temperature, after which the cells were fixed and analyzed immediately by flow cytometry. Flow cytometry analysis was performed using a CyAn flow cytometer (Beckman Coulter) and the Summit analysis software.

Dexamethasone-loaded platelets were prepared by incubating $1 \mathrm{ml}$ of platelets $(250,000 / \mathrm{ul})$ in citrated saline with $5 \mathrm{ul}$ of dexamethasone (Sigma, $10 \mathrm{mM}$ in DMSO) for $15 \mathrm{~min}$ on a rocker at room temperature. Platelets were then washed three times with citrated saline to remove unbound dexamethasone. For subsequent experiments, $5 \times 10^{6}$ dex-platelets were added to each well of macrophages in a 24-well plate.

To prepare apoptotic cells, PBMCs were isolated as above, and following monocyte-adherence to gelatincoated flasks the non-adherent lymphocytes were collected. Cells were rendered apoptotic (Annexin-V positive) by UV-irradiation for $10 \mathrm{~min}$ followed by overnight incubation in RPMI $+10 \% \mathrm{FBS}$ at $37^{\circ} \mathrm{C}+5 \% \mathrm{CO}$.

\section{Phagocytosis Experiments}

Thirty minutes prior to the start of each experiment, 7-day old MDMs were washed 3 times with PBS and incubated with $500 \mu$ fresh RPMI media. In some experiments the 
media was supplemented with $10 \%$ autologous human serum. A $25 \mu \mathrm{l}$ aliquot of fluorescently labeled platelets $(250,000 / \mu \mathrm{l})$ was added to each well of macrophages. Platelets and macrophages were co-incubated for $45 \mathrm{~min}$.

For SEM analysis, the co-cultures were washed once with PBS and fixed in 2\% paraformaldehyde and 0.5\% glutaraldehyde. The samples were then processed as previously described [33] and examined using a Cambridge S200 scanning electron microscope at $20 \mathrm{kV}$. For TEM analysis, the co-cultures were washed 5 times with PBS and fixed in $2 \%$ paraformaldehyde, processed as previously described [34], and examined using a Leo EM 910 transmission electron microscope. For flow cytometric analysis, warm trypsin/EDTA was then added to the macrophages to remove adherent platelets (confirmed by microscopy) and cells were incubated $15 \mathrm{~min}$ at $37^{\circ} \mathrm{C}$. Macrophages were then collected and fixed in $1 \%$ cold paraformaldehyde and analyzed using a CyAn flow cytometer (Beckman Coulter) and the Summit analysis software. Data is expressed as the percentage of FL1-positive macrophages in a given collection of 10,000 macrophages. Data shown represent the average of at least 3 independent experiments and for each experiment 10,000 macrophages were analyzed.

Latrunculin (Sigma, $1 \mu \mathrm{g} / \mathrm{ml}$ final concentration), used as a pan-phagocytosis inhibitor, was added to a portion of macrophage-containing wells $30 \mathrm{~min}$ prior to addition of platelets. Fucoidan (Sigma) was added to macrophages at a final concentration of $250 \mu \mathrm{g} / \mathrm{ml} 30 \mathrm{~min}$ prior to addition of platelets.

\section{Cytokine Experiments}

Each well of MDMs was washed 3 times with PBS and incubated with fresh RPMI $+10 \%$ autologous human serum. Activated, degranulated, or dexamethasoneloaded platelets $\left(5 \times 10^{6}\right)$ were added to each well in addition to LPS $(100 \mathrm{ng} / \mathrm{ml})$. Some samples also received dexamethasone alone at a final concentration of $1 \mu \mathrm{M}$. After $24 \mathrm{hrs}$, supernatants were collected, spun $10 \mathrm{~min}$ at $14,000 \mathrm{~g}$, and frozen at $-80^{\circ} \mathrm{C}$. Cytokines were measured by ELISA using capture and detection antibodies (eBioscience) per the manufacturer's instructions. Cytokines were measured in duplicate and averaged. The amount of protein secreted was normalized to the amount secreted by macrophages treated with LPS alone. Each experiment was performed at least 3 times using 3 different MDM donors. In each experiment, the platelets added were from the same donor as the MDMs. Treatment groups were compared using an unpaired t-test.

\section{Results}

Macrophage Phagocytosis of Autologous Platelets

To examine the interaction between human MDMs (hMDMs) and autologous platelets, we utilized an in vitro co-culture system consisting of 7 -day old hMDMs to which we added freshly isolated autologous platelets. The use of autologous platelets excludes the possibility that platelet-macrophage interactions are the result of an immune response triggered by the recognition of platelets as 'foreign.' The hMDMs and platelets were first co-cultured in serum-free RPMI media and examined by SEM and TEM at various time points to visualize the interaction between these two different cell types. As shown in Figure 1A, we observed platelets interacting with hMDMs during the first hour of coculture. Platelets near the macrophages became entrapped by a network of macrophage filopodia, and although the macrophages were firmly attached to the coverslip and did not migrate, they appeared to direct groups of filopodia in the direction of nearby platelets that had settled on the dish. Visualization of these cultures suggests that an interaction between human macrophages and autologous activated platelets (AAPs) occurs in vitro, and that it occurs in the absence of serum proteins.

Platelet phagocytosis by the macrophages in our coculture system was subsequently confirmed by TEM and flow cytometry. Macrophages that were co-incubated with AAPs for one hour developed vacuoles, many of which contained contents that were the same size and shape as platelets (Figure 1B). These phagocytic vacuoles did not appear in control macrophages cultured in the absence of platelets. We then quantified phagocytosis by flow cytometric analysis of macrophage fluorescence after co-incubation with fluorescently labeled platelets and removal of adherent platelets with trypsin. When freshly isolated platelets were incubated in serum-free RPMI media and added in excess to 7-day old macrophages, approximately $50 \%$ of the macrophages internalized at least one platelet within $45 \mathrm{~min}$ (Figure 2). As expected, pretreatment of the hMDMs with the actin inhibitor latrunculin almost completely blocked phagocytosis, confirming the role of actin polymerization that occurs in all cases of phagocytosis (Figure 2A). The amount of phagocytosis increased if the platelets were pre-stimulated with thrombin (Figure 2B), and was significantly inhibited in the presence of fucoidan, a known competitive inhibitor to Scavenger Receptors [35,36] (Figure 2C). The presence of $10 \%$ autologous human serum had no significant effect on phagocytosis, which excludes the possibility that the platelet-macrophage interaction requires a soluble serum-bound "bridging" molecule. Together these results suggest that phagocytosis of platelets correlates with platelet activation, and that macrophage phagocytosis of autologous platelets may be mediated, at least in part, by scavenger receptors.

We also used flow cytometry to more accurately examine the level of platelet activation in different culture 


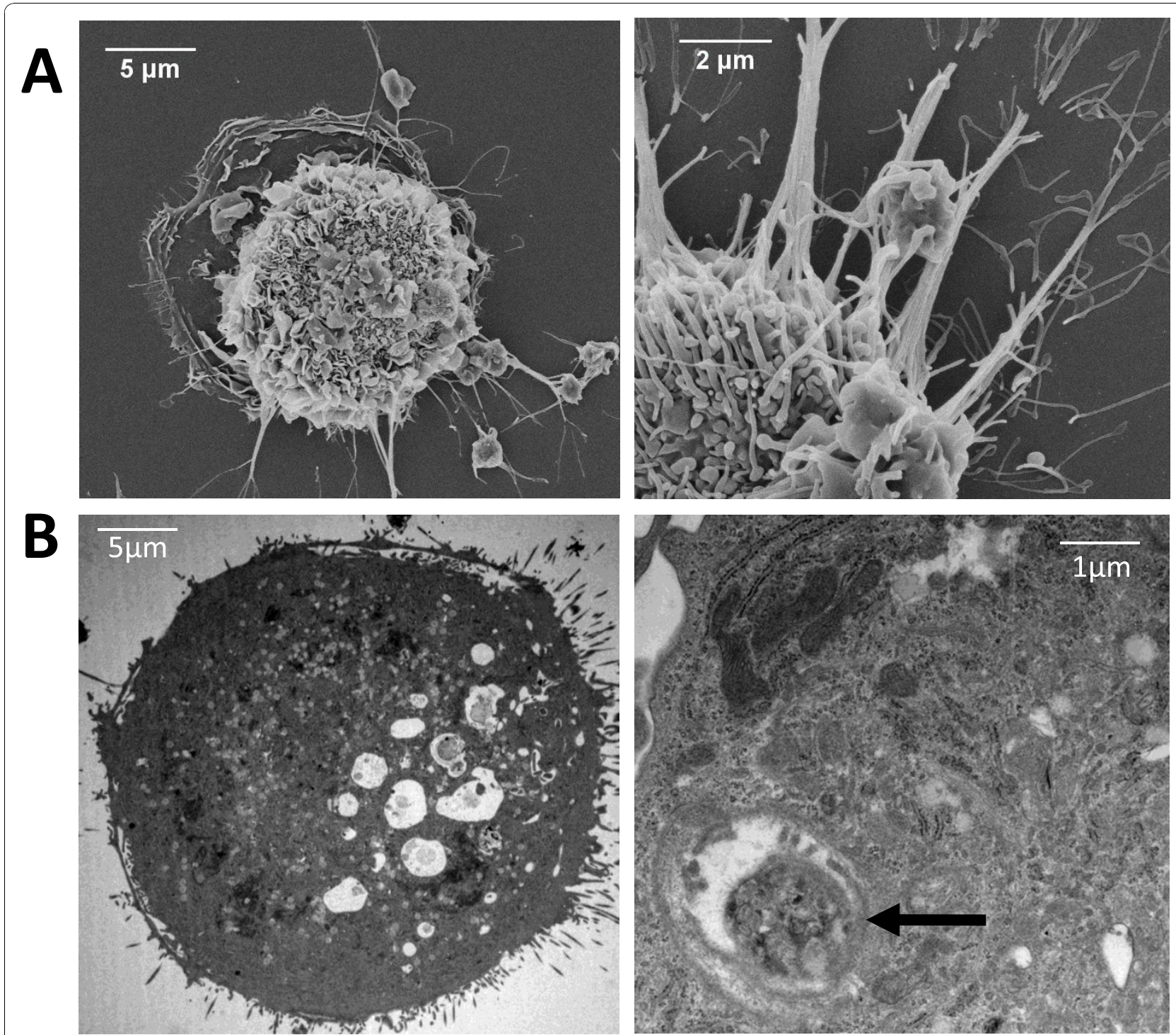

Figure 1 Electron Microscopic Analysis of Platelet-Macrophage Interactions. (A) hMDMs were incubated with fresh AAPs for 15 min (left panel) or $45 \mathrm{~min}$ (right panel) before processing for SEM analysis. (B) TEM analysis of hMDMs after $1 \mathrm{hr}$ co-incubation with platelets. Arrow indicates phagocytic vacuole at high magnification.

conditions. Platelets were analyzed for expression of P-selectin, an alpha granule component expressed during early platelet activation, and phosphatidylserine, a membrane lipid exposed on the surface of completely (and irreversibly) activated platelets. Incubation in serum-free media alone for 1 hour resulted in an approximately tenfold increase in P-selectin expression but did not induce surface expression of phosphatidylserine (Table 1). Treatment of platelets with thrombin, known to cause complete degranulation and irreversible platelet activation [23,37], resulted in even higher levels of P-selectin and also increased surface expression of phosphatidylserine (Table 1). Interestingly, the data in Figures 1 and 2 showing phagocytosis of platelets incubated only in RPMI media suggests that only partial platelet activation, in the absence of complete degranulation or phosphatidylserine exposure, is sufficient to trigger phagocytosis. Although phagocytosis was enhanced when the platelets did express phosphatidylserine, we conclude that surface exposure of phosphatidylserine is not an absolute requirement for phagocytosis of platelets.

\section{Inflammatory Cytokines are Enhanced Following Platelet Phagocytosis}

The hypothesis that macrophage phagocytosis of activated platelets results in an inflammatory response that differs from the response following phagocytosis of apoptotic cells was tested by measuring the secretion of 
Table 1 Platelet Activation in Co-Culture Conditions

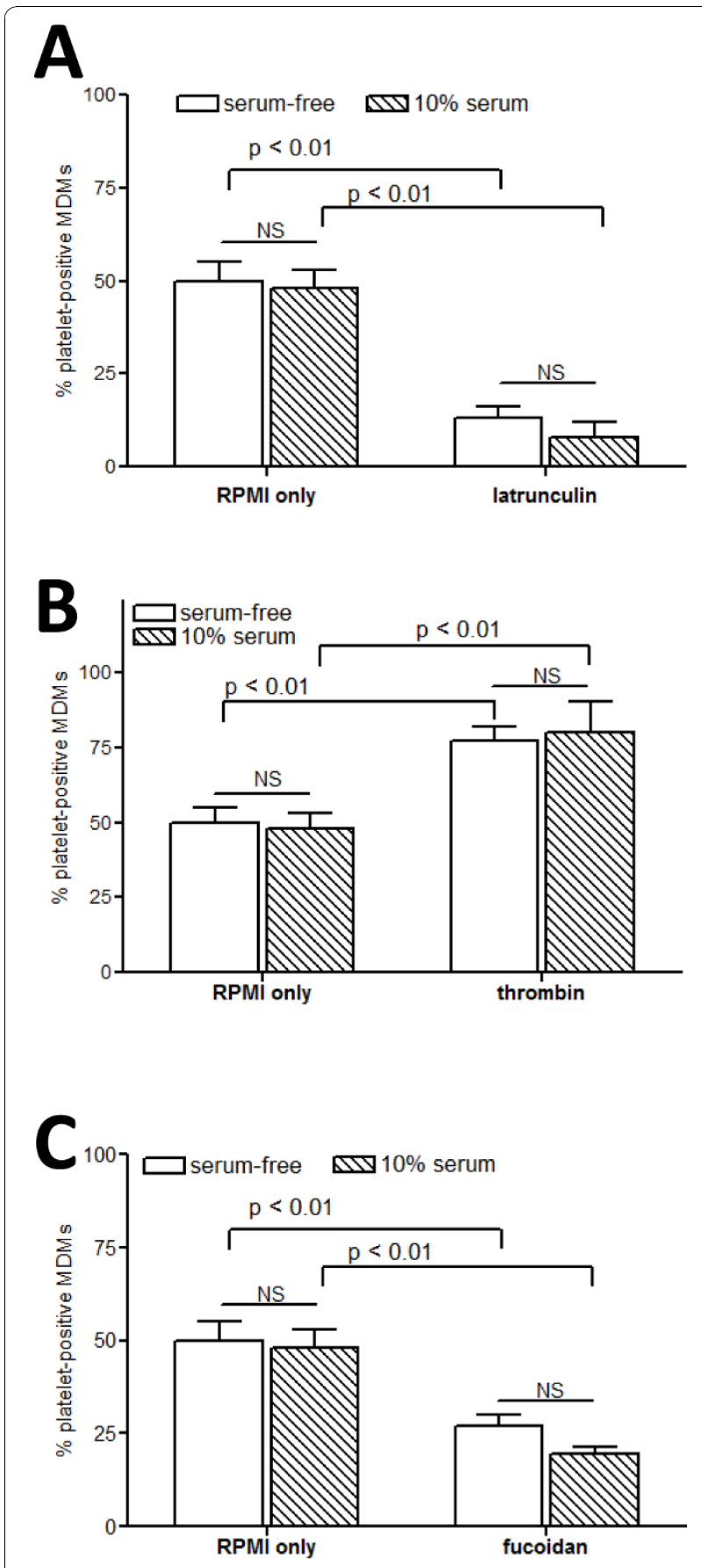

Figure 2 Flow Cytometric Analysis of Platelet Phagocytosis. hMDMs were incubated with an excess of fluorescently labeled platelets for 45 min in RPMI media alone (white bars) or containing $10 \%$ autologous human serum (striped bars). Macrophage fluorescence was measured by flow cytometry and the average percentage of FL1-positive macrophages after removal of adherent platelets are shown for 3 independent experiments for each sample. Data for control samples are repeated in each panel, and compared to treatment with (A) latrunculin $(1 \mathrm{ug} / \mathrm{ml})$, (B) thrombin $(0.1 \mathrm{U} / \mathrm{ml})$, or (C) fucoidan $(250 \mathrm{ug} / \mathrm{ml})$. Statistically significant differences are indicated with their corresponding $\mathrm{p}$-values. The addition of $10 \%$ serum did not result in any statistically significant difference (NS).

\begin{tabular}{ccc}
\hline & P-selectin & Phosphatidylserine \\
\hline citrated saline control & $15.2+/-3.0$ & $8.9+/-0.9$ \\
\hline RPMI 1 hour & $178.5+/-33.1$ & $11.3+/-3.1$ \\
\hline thrombin & $1471.3+/-155.8$ & $1599.9+/-464.5$
\end{tabular}

Platelets were analyzed for platelet activation markers by flow cytometry as described in Methods. Values are expressed as Mean Fluorescence Intensity, and are the averages ( + - standard error) of at least 3 independent experiments.

cytokines following addition of platelets or apoptotic cells to LPS-stimulated hMDMs. Autologous platelets in two different activation states were used in the coculture experiments: platelets that were "partially activated" (with surface exposure of measurable quantities of P-selectin and CD40L) by preparing in serum-free media or "irreversibly activated" (with phosphatidylserine exposure in addition to P-selectin) by treatment with the calcium ionophore A23187 [37].

The inflammatory response of the hMDMs was assessed by measuring the levels of TNF- $\alpha$, IL- 6 , and IL-23 after incubation with autologous primed platelets, autologous activated platelets, or control apoptotic leukocytes in the presence of LPS for 24 hours. As an additional control, we analyzed "platelets-only" cultures using the same media and incubation times as the platelet-macrophage co-cultures and were unable to detect any TNF- $\alpha$, IL-6, or IL-23 in platelets alone (with or without LPS, data not shown). We therefore conclude that the cytokines secreted in this system are macrophage-derived, and in each experiment the cytokine levels were normalized to the amount of cytokine secreted by hMDMs incubated with LPS alone.

When compared to LPS stimulation alone, macrophage co-incubation with apoptotic cells inhibited LPS-induced secretion of all three pro-inflammatory cytokines (Figure 3A, grey bars). However, co-incubation with primed or activated platelets enhanced macrophage secretion of TNF- $\alpha$, IL-6, and IL-23. Induction of proinflammatory cytokines in the presence of platelets was 20-60\% higher than the levels obtained by LPS treatment alone. Furthermore, the macrophage cytokine secretion was enhanced to a similar degree after coincubation with both partially activated and degranulated platelets (Figure 3A). These data suggest activated platelets enhance LPS-induced macrophage cytokine secretion even when they present phosphatidylserine to the macrophage.

Based on the knowledge that platelets can bind glucocorticoids via glucocorticoid receptors [38], we tested the hypothesis that glucocorticoid-bound platelets would be less inflammatory than platelets that are activated, but otherwise unmodified. Platelets were incubated with dexamethasone, then unbound glucocorticoid was removed by washing the platelets in citrated saline. Although it is 


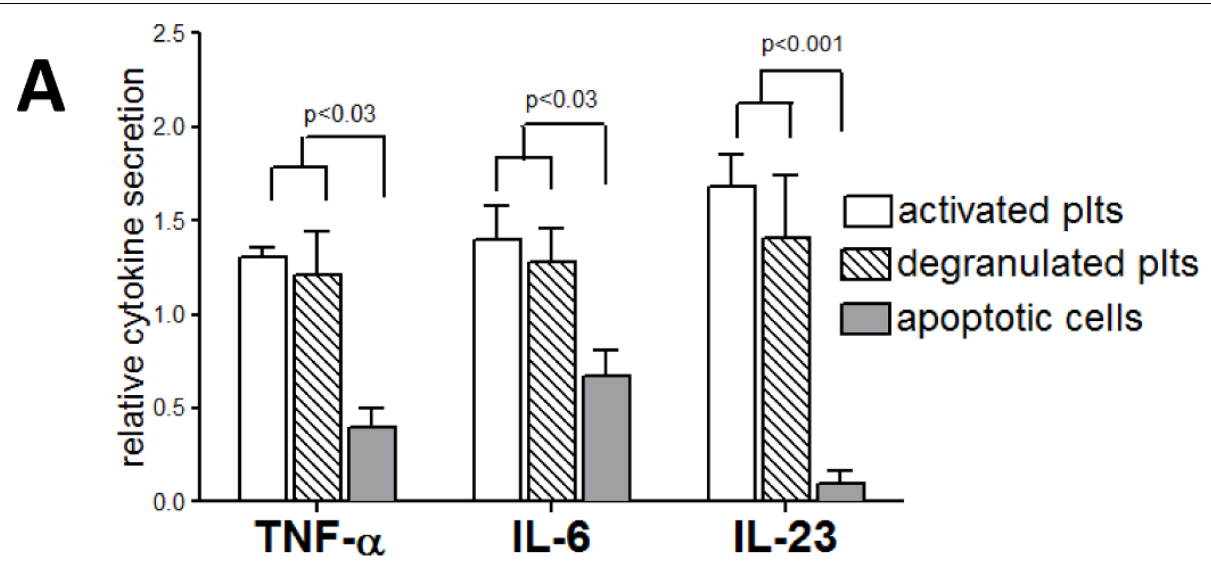

B

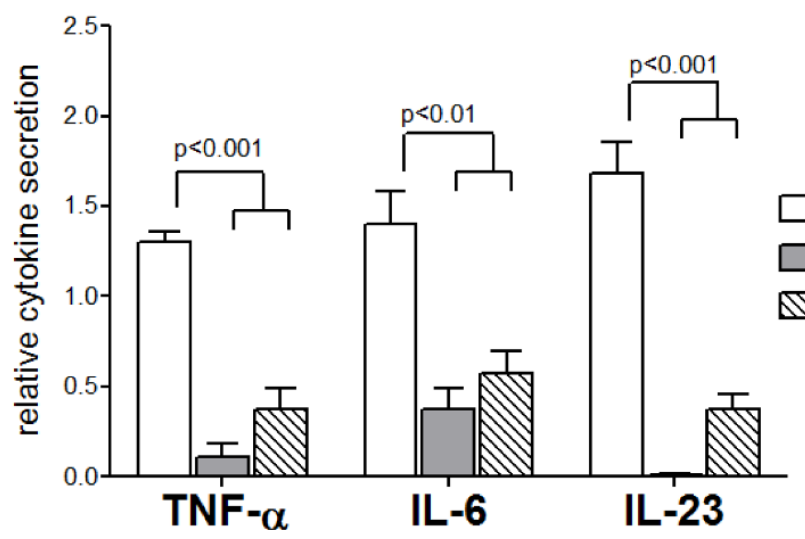

Figure 3 Cytokine analysis of macrophages in the presence of activated platelets, apoptotic cells, and dexamethasone. Cytokines were measured by ELISA 24 hrs after stimulation with LPS $(100 \mathrm{ng} / \mathrm{ml})$ in the presence or absence of (A) apoptotic cells or platelets, and (B) dexamethasone alone $(1 \mu \mathrm{M})$ or dexamethasone-loaded platelets. Data for activated platelets is repeated in both panels. Cytokine levels are expressed relative to treatment with LPS only. Macrophages were incubated with equivalent numbers of platelets in each condition. Shown are the averages of at least 3 independent experiments. Statistically significant differences are indicated with corresponding p-values.

unlikely that all of the dexamethasone becomes bound to the platelets, complete retention of the dexamethasone would yield a final concentration in the DEX-plt stock of $50 \mu \mathrm{M}$ and a final (effective) concentration in the platelet-macrophage co-cultures of $1 \mu \mathrm{M}$. As shown in Figure 3B (striped bars), the levels of cytokines produced after co-culture with dexamethasone-loaded platelets were inhibited to $30-50 \%$ of the levels produced by stimulation with LPS alone. The dexamethasone-loaded platelets had a similar effect on cytokine secretion as $1 \mu \mathrm{M}$ dexamethasone alone. These results indicate that the proinflammatory platelet effect on macrophage activation can be reversed by pre-loading the platelets with glucocorticoids.

\section{Discussion}

Phagocytosis is an important means of clearing both immunologically compromised and apoptotic cells. Monocyte-derived macrophages are efficient phagocytes in organs of the reticuloendothelial system and within injured tissues; however, the process of platelet clearance by macrophages is poorly understood. This work has demonstrated phagocytosis of fresh autologous activated platelets (AAPs) by monocyte-derived macrophages using an entirely human-derived in vitro system. In this system, uptake of freshly isolated platelets is dependent on actin polymerization, but occurs independently of any soluble serum factors. Additionally, phagocytosis of platelets is enhanced with platelet activation.

Previous studies on platelet phagocytosis have focused on modified platelets such as chilled platelets, opsonized platelets, and aged platelets [39-46], each of which involves distinct changes to the platelet surface. Aged platelets most closely resemble freshly activated platelets because during aging platelets increase expression of phosphatidylserine and P-selectin [20]. Interestingly, Brown et al. have also shown in vitro that phagocytosis of aged platelets is mediated by scavenger receptors [20]. 
Therefore, macrophages may recognize freshly activated platelets in the same way that they clear aged platelets. The finding that phosphatidylserine exposure is not a requirement for phagocytosis of AAPs in the present study was somewhat unexpected, considering that phosphatidylserine is a well documented 'eat me' signal for the phagocytosis of many different types of cells undergoing apoptosis [47-50].

Because phagocytosis correlates with platelet activation, we would expect no phagocytosis to occur in the presence of quiescent platelets. However, RPMI media alone causes platelet activation (Table 1), probably due to the presence of low levels of calcium and phosphate. Additionally, the use of platelet inhibitors such as aspirin, EDTA, or prostaglandin, which may have maintained the platelets in a resting state, could not be used because they directly affect macrophage function [51,52]. Thus, one disadvantage of our system is that the plateletmacrophage interaction using activated platelets could not be compared to an interaction in which the platelets were in a truly resting state. Nonetheless, the interaction involving activated platelets is relevant because platelets are most likely activated at sites of tissue injury and perhaps during removal in the spleen. Thus, the interaction involving activated platelets was the focus of this work.

The macrophage response following phagocytosis of cells expressing surface phosphatidylserine is usually immunosuppressive $[2,26,27,53,54]$. In the present study, co-culture with apoptotic cells inhibited production of pro-inflammatory cytokines by LPS-activated macrophages. These results are in agreement with previous findings for TNF- $\alpha$, IL- $1 \beta$, IL- 8, IL-12 $[2,4,55,56]$, and are extended to now include IL-6 and IL-23.

In contrast to the effect of apoptotic cells, activated platelets enhanced pro-inflammatory cytokine secretion from LPS-activated macrophages. The cytokines measured in the current study, TNF- $\alpha$, IL- 6 and IL-23, are significant readouts because they are known to be secreted by macrophages, but not platelets, and they play important roles in mediating pro-inflammatory responses. Interestingly, the pro-inflammatory cytokine secretion was also enhanced by platelets with surface phosphatidylserine exposure. The finding that degranulated platelets, washed free from their secreted proteins, also enhanced LPS-induced macrophage cytokine secretion suggests that a secreted platelet factor is not likely to be responsible for this effect. However, a secreted platelet factor could exert the observed effect if it remained bound to the platelet surface after secretion from the platelet. Because the platelets remained in the co-incubation for the entire experiment ( $24 \mathrm{hrs})$, the possibility also exists that the inflammatory consequences of plateletmacrophage interactions occur independently of phagocytosis. Cell contact itself could be responsible for the observed effects. Nonetheless, we have shown the proinflammatory effect of platelets does occur in conditions which favor platelet uptake (Figure 1).

Recent studies have highlighted additional roles of platelets beyond hemostasis, particularly with respect to platelet-mediated effects on inflammation $[28,57,58]$. These results are particularly relevant to chronic inflammatory diseases, during which macrophages may interact with apoptotic or necrotic cells, as well as platelets, for prolonged periods of time. Studies in mice have demonstrated that depletion of platelets or platelet proteins affects macrophage infiltration and inflammation in lesions of the skin, joints, gut, and vasculature [59-63]. Although the precise mechanisms by which platelets impact macrophage activation remain unclear, the current study provides direct evidence, using human cells, of specific macrophage cytokines that are enhanced by activated platelets.

Pro-inflammatory cytokines secreted by macrophages can also exert effects on surrounding cells and tissues. For example, IL-6 and IL-23 stimulate T-cells for induction of Th17 immune responses, which are operant in autoimmune diseases such as inflammatory bowel disease, lupus, psoriasis and arthritis [64-67]. We speculate, therefore, that in addition to amplifying general pro-inflammatory responses, platelet-macrophage interactions might also play a role in Th17-mediated autoimmune diseases.

Glucocorticoids such as dexamethasone can exert powerful immunosuppressive effects on leukocytes and are thus an attractive therapy for modulating inflammation [68]. After steroid binding to glucocorticoid receptors, which occurs within the cytoplasm, activated glucocorticoid receptors translocate to the nucleus and inhibit transcription of a variety of pro-inflammatory cytokines [68]. We speculate, therefore, that the immunosuppressive action of dexamethasone-loaded platelets occurs by facilitating delivery of dexamethasone to macrophage glucocorticoid receptors. Because macrophage glucocorticoid receptors are cytoplasmic, we further speculate that the immunosuppressive effect of dex-platelets is a result of phagocytosis. The use of dexamethasone-loaded platelets for modulating macrophage action may prove useful in treating diseases characterized by excessive and unresolving inflammation. Our results demonstrating similar levels of immunosuppression with both free dexamethasone and dexamethasone bound to platelets suggests that tethering glucocorticoids to platelets may increase drug targeting and reduce the need for high systemic doses of glucocorticoids, which can have unwanted side effects [69]. Furthermore, given the role of IL-6 and IL-23 in Th17-mediated inflammatory responses, the platelet-macrophage interaction is therefore a rational pharmacological target for inhibiting some Th17-related diseases. 


\section{Conclusions}

We have shown here that the interaction of human macrophages with autologous platelets results in scavenger-receptor-mediated platelet uptake and enhancement of LPS-induced cytokine secretion. Given the presence of activated platelets together with macrophages during the response to injury and during inflammation, activated platelets at sites of inflammation most likely exacerbate the macrophage response. The presence of platelets must therefore be carefully considered when studying the cellular interactions occurring in inflammatory lesions.

We have also presented evidence here that platelets can be engineered to exert anti-inflammatory effects on macrophages. Given the emerging role of platelets in inflammatory diseases, the possibility of reversing macrophage activation with dexamethasone-loaded platelets is a promising therapeutic approach to treating unresolved inflammation.

\section{Acknowledgements \\ This work was supported by sponsored research funds from Entegrion, Inc (Research Triangle Park, NC, USA) and a collaborative research grant from the North Carolina Biotechnology Center}

\section{Authors' contributions}

CMS conceived of the study, participated in its design and coordination, performed phagocytosis assays and cytokine measurements, and drafted the manuscript. WDH participated in the design of the study, coordinated the selection and participation of blood donors, and processed the blood samples. THF was the principal investigator on this project and provided guidance and advice on the experiments and manuscript. All authors read and approved the final manuscript.

\section{Competing interests}

The authors declare that they have no competing interests.

Received: 16 June 2010 Accepted: 11 November 2010 Published: 11 November 2010

\section{References}

1. Aderem A: Phagocytosis and the inflammatory response. J Infect Dis 2003, 187(Suppl 2):S340-345.

2. Chung EY, Kim SJ, Ma XJ: Regulation of cytokine production during phagocytosis of apoptotic cells. Cell Res 2006, 16:154-161.

3. Birge RB, Ucker DS: Innate apoptotic immunity: the calming touch of death. Cell Death Differ 2008, 15:1096-1102.

4. Fadok VA, Bratton DL, Konowal A, Freed PW, Westcott JY, Henson PM: Macrophages that have ingested apoptotic cells in vitro inhibit proinflammatory cytokine production through autocrine/paracrine mechanisms involving TGF-beta, PGE2, and PAF. J Clin Invest 1998, 101:890-898.

5. Li Y, Gerbod-Giannone MC, Seitz H, Cui D, Thorp E, Tall AR, Matsushima GK, Tabas I: Cholesterol-induced apoptotic macrophages elicit an inflammatory response in phagocytes, which is partially attenuated by the Mer receptor. J Biol Chem 2006, 281:6707-6717.

6. Henson PM, Hume DA: Apoptotic cell removal in development and tissue homeostasis. Trends Immunol 2006, 27:244-250.

7. Rosqvist R, Bolin I, Wolf-Watz H: Inhibition of phagocytosis in Yersinia pseudotuberculosis: a virulence plasmid-encoded ability involving the Yop2b protein. Infect Immun 1988, 56:2139-2143.

8. Casanova JL, Abel L: Revisiting Crohn's disease as a primary immunodeficiency of macrophages. J Exp Med 2009, 206:1839-1843,

9. Oncul O, Yildiz S, Gurer US, Yeniiz E, Qyrdedi T, Top C, Gocer P, Akarsu B, Cevikbas A, Cavuslu S: Effect of the function of polymorphonuclear leukocytes and interleukin-1 beta on wound healing in patients with diabetic foot infections. J Infect 2007, 54:250-256.

10. Maree AF, Komba M, Finegood DT, Edelstein-Keshet L: A quantitative comparison of rates of phagocytosis and digestion of apoptotic cells by macrophages from normal (BALB/c) and diabetes-prone (NOD) mice. J Appl Physiol 2008, 104:157-169.

11. Tabas I: Consequences and therapeutic implications of macrophage apoptosis in atherosclerosis: the importance of lesion stage and phagocytic efficiency. Arterioscler Thromb Vasc Biol 2005, 25:2255-2264.

12. Mukhopadhyay S, Pluddemann A, Gordon S: Macrophage pattern recognition receptors in immunity, homeostasis and self tolerance. Adv Exp Med Biol 2009, 653:1-14.

13. Albert ML, Kim Jl, Birge RB: alphavbeta5 integrin recruits the CrkllDock180-rac1 complex for phagocytosis of apoptotic cells. Nat Cell Biol 2000, 2:899-905.

14. Fadok VA, Savill JS, Haslett C, Bratton DL, Doherty DE, Campbell PA, Henson PM: Different populations of macrophages use either the vitronectin receptor or the phosphatidylserine receptor to recognize and remove apoptotic cells. J Immunol 1992, 149:4029-4035.

15. Fadok VA, Warner ML, Bratton DL, Henson PM: CD36 is required for phagocytosis of apoptotic cells by human macrophages that use either a phosphatidylserine receptor or the vitronectin receptor (alpha $v$ beta 3). J Immunol 1998, 161:6250-6257.

16. Gregory CD: CD14-dependent clearance of apoptotic cells: relevance to the immune system. Curr Opin Immunol 2000, 12:27-34.

17. Hart SP, Dransfield I, Rossi AG: Phagocytosis of apoptotic cells. Methods 2008, 44:280-285.

18. Platt N, Suzuki H, Kurihara Y, Kodama T, Gordon S: Role for the class A macrophage scavenger receptor in the phagocytosis of apoptotic thymocytes in vitro. Proc Natl Acad Sci USA 1996, 93:12456-12460.

19. Savill J, Fadok V, Henson P, Haslett C: Phagocyte recognition of cells undergoing apoptosis. Immunol Today 1993, 14:131-136.

20. Brown SB, Clarke MC, Magowan L, Sanderson H, Savill J: Constitutive death of platelets leading to scavenger receptor-mediated phagocytosis. A caspase-independent cell clearance program. J Biol Chem 2000, 275:5987-5996.

21. Andre P: P-selectin in haemostasis. Br J Haematol 2004, 126:298-306.

22. Zwaal RF, Bevers EM: Platelet phospholipid asymmetry and its significance in hemostasis. Subcell Biochem 1983, 9:299-334.

23. Heemskerk JW, Bevers EM, Lindhout T: Platelet activation and blood coagulation. Thromb Haemost 2002, 88:186-193.

24. Djaldetti M, Salman H, Bergman M, Djaldetti R, Bessler H: Phagocytosis-the mighty weapon of the silent warriors. Microsc Res Tech 2002, 57:421-431.

25. Ravichandran KS, Lorenz U: Engulfment of apoptotic cells: signals for a good meal. Nat Rev Immunol 2007, 7:964-974.

26. Gregory CD, Devitt A: The macrophage and the apoptotic cell: an innate immune interaction viewed simplistically? Immunology 2004, 113:1-14.

27. Voll RE, Herrmann M, Roth EA, Stach C, Kalden JR, Girkontaite I: Immunosuppressive effects of apoptotic cells. Nature 1997, 390:350-351.

28. Smyth SS, McEver RP, Weyrich AS, Morrell CN, Hoffman MR, Arepally GM, French PA, Dauerman HL, Becker RC: Platelet functions beyond haemostasis. J Thromb Haemost 2009, 7(11):1759-66.

29. Weyrich AS, Lindemann S, Zimmerman GA: The evolving role of platelets in inflammation. J Thromb Haemost 2003, 1:1897-1905.

30. Jones BM, Nicholson JK, Holman RC, Hubbard M: Comparison of monocyte separation methods using flow cytometric analysis. J Immunol Methods 1989, 125:41-47.

31. Hassan NF, Campbell DE, Douglas SD: Purification of human monocytes on gelatin-coated surfaces. J Immunol Methods 1986, 95:273-276.

32. Baker GR, Sullam PM, Levin J: A simple, fluorescent method to internally label platelets suitable for physiological measurements. Am J Hematol 1997, 56:17-25.

33. Fischer TH, Robbins ME, Bode AP, Nichols TC, Bellinger DE, Schoenfisch MH: Evidence that rehydrated, lyophilized red blood cells are sufficiently deformable for normal microcirculation transit. Microsc Res Tech 2004, 65:62-71.

34. Sanders WE, Read MS, Reddick RL, Garris JB, Brinkhous KM: Thrombotic thrombocytopenia with von Willebrand factor deficiency induced by botrocetin. An animal model. Lab Invest 1988, 59:443-452.

35. Nakamura T, Suzuki H, Wada Y, Kodama T, Doi T: Fucoidan induces nitric oxide production via p38 mitogen-activated protein kinase and NF- 
kappaB-dependent signaling pathways through macrophage scavenger receptors. Biochem Biophys Res Commun 2006, 343:286-294.

36. Krieger $\mathrm{M}$, Herz J: Structures and functions of multiligand lipoprotein receptors: macrophage scavenger receptors and LDL receptor-related protein (LRP). Annu Rev Biochem 1994, 63:601-637.

37. White JG, Rao GH, Gerrard JM: Effects of the lonophore A23187 on blood platelets I. Influence on aggregation and secretion. Am J Pathol 1974, 77:135-149.

38. Moraes LA, Paul-Clark MJ, Rickman A, Flower RJ, Goulding NJ, Perretti M: Ligand-specific glucocorticoid receptor activation in human platelets. Blood 2005, 106:4167-4175.

39. Hoffmeister KM, Felbinger TW, Falet H, Denis CV, Bergmeier W, Mayadas TN, von Andrian UH, Wagner DD, Stossel TP, Hartwig JH: The clearance mechanism of chilled blood platelets. Cell 2003, 112:87-97.

40. Badlou BA, Spierenburg G, Ulrichts H, Deckmyn H, Smid WM, Akkerman JW: Role of glycoprotein Ibalpha in phagocytosis of platelets by macrophages. Transfusion 2006, 46:2090-2099.

41. Badlou BA, Wu YP, Smid WM, Akkerman JW: Platelet binding and phagocytosis by macrophages. Transfusion 2006, 46:1432-1443.

42. Josefsson EC, Gebhard HH, Stossel TP, Hartwig JH, Hoffmeister KM: The macrophage alphaMbeta2 integrin alphaM lectin domain mediates the phagocytosis of chilled platelets. J Biol Chem 2005, 280:18025-18032.

43. Babic AM, Josefsson EC, Bergmeier W, Wagner DD, Kaufman RM, Silberstein LE, Stossel TP, Hartwig JH, Hoffmeister KM: In vitro function and phagocytosis of galactosylated platelet concentrates after long-term refrigeration. Transfusion 2007, 47:442-451.

44. Bondanza A, Sabbadini MG, Pellegatta F, Zimmermann VS, Tincani A Balestrieri G, Manfredi AA, Rovere P: Anti-beta2 glycoprotein I antibodies prevent the De-activation of platelets and sustain their phagocytic clearance. J Autoimmun 2000, 15:469-477.

45. Roubey RA: Immunology of the antiphospholipid syndrome: antibodies, antigens, and autoimmune response. Thromb Haemost 1999, 82:656-661.

46. Roubey RA: Systemic lupus erythematosus, hypercoagulable states, and antiphospholipid antibodies. Arthritis Care Res 1999, 12:155-156.

47. Wu Y, Tibrewal N, Birge RB: Phosphatidylserine recognition by phagocytes: a view to a kill. Trends Cell Biol 2006, 16:189-197.

48. Bratosin D, Mazurier J, Tissier JP, Estaquier J, Huart JJ, Ameisen JC, Aminoff $D$, Montreuil J: Cellular and molecular mechanisms of senescent erythrocyte phagocytosis by macrophages. A review. Biochimie 1998, 80:173-195.

49. Schlegel RA, Callahan M, Krahling S, Pradhan D, Williamson P: Mechanisms for recognition and phagocytosis of apoptotic lymphocytes by macrophages. Adv Exp Med Biol 1996, 406:21-28.

50. Guzik K, Potempa J: Friendly fire against neutrophils: proteolytic enzymes confuse the recognition of apoptotic cells by macrophages. Biochimie 2008, 90:405-415.

51. Lu L, Liu H, Peng J, Gan L, Shen L, Zhang Q, Li L, Zhang L, Su C, Jiang Y: Regulations of the key mediators in inflammation and atherosclerosis by aspirin in human macrophages. Lipids Health Dis 2010, 9:16.

52. Kunkel SL, Spengler M, May MA, Spengler R, Larrick J, Remick D: Prostaglandin E2 regulates macrophage-derived tumor necrosis factor gene expression. J Biol Chem 1988, 263:5380-5384.

53. Aderem A, Underhill DM: Mechanisms of phagocytosis in macrophages. Annu Rev Immunol 1999, 17:593-623.

54. Maderna P, Godson C: Phagocytosis of apoptotic cells and the resolution of inflammation. Biochim Biophys Acta 2003, 1639:141-151.

55. Kim S, Elkon KB, Ma X: Transcriptional suppression of interleukin-12 gene expression following phagocytosis of apoptotic cells. Immunity 2004, 21:643-653.

56. Lucas M, Stuart LM, Savill J, Lacy-Hulbert A: Apoptotic cells and innate immune stimuli combine to regulate macrophage cytokine secretion. $J$ Immunol 2003, 171:2610-2615.

57. Leslie M: Cell biology. Beyond clotting: the powers of platelets. Science 2010, 328:562-564.

58. Page CP: Platelets as inflammatory cells. Immunopharmacology 1989 17:51-59.

59. Katoh N: Platelets as versatile regulators of cutaneous inflammation. $J$ Dermatol Sci 2009, 53:89-95.

60. Boilard E, Nigrovic PA, Larabee K, Watts GF, Coblyn JS, Weinblatt ME, Massarotti EM, Remold-O'Donnell E, Farndale RW, Ware J, Lee DM: Platelets amplify inflammation in arthritis via collagen-dependent microparticle production. Science 2010, 327:580-583.

61. Danese S, de la Motte C, Sturm A, Vogel JD, West GA, Strong SA, Katz JA, Fiocchi C: Platelets trigger a CD40-dependent inflammatory response in the microvasculature of inflammatory bowel disease patients. Gastroenterology 2003, 124:1249-1264.

62. Wagner DD, Burger PC: Platelets in inflammation and thrombosis. Arterioscler Thromb Vasc Biol 2003, 23:2131-2137.

63. Kockx MM, Cromheeke KM, Knaapen MW, Bosmans JM, De Meyer GR Herman AG, Bult H: Phagocytosis and macrophage activation associated with hemorrhagic microvessels in human atherosclerosis. Arterioscler Thromb Vasc Biol 2003, 23:440-446.

64. Brand S: Crohn's disease: Th1, Th17 or both? The change of a paradigm: new immunological and genetic insights implicate Th17 cells in the pathogenesis of Crohn's disease. Gut 2009, 58:1152-1167.

65. Mangini AJ, Lafyatis R, Van Seventer JM: Type I interferons inhibition of inflammatory Thelper cell responses in systemic lupus erythematosus. Ann N Y Acad Sci 2007, 1108:11-23.

66. Annunziato F, Cosmi L, Liotta F, Maggi E, Romagnani S: Type 17 T helper cells-origins, features and possible roles in rheumatic disease. Nat Rev Rheumatol 2009, 5:325-331.

67. van der Fits L, Mourits S, Voerman JS, Kant M, Boon L, Laman JD, Cornelissen F, Mus AM, Florencia E, Prens EP, Lubberts E: Imiquimodinduced psoriasis-like skin inflammation in mice is mediated via the IL23/LL-17 axis. J Immunol 2009, 182:5836-5845.

68. Barnes PJ: Anti-inflammatory actions of glucocorticoids: molecular mechanisms. Clin Sci (Lond) 1998, 94:557-572.

69. McDonough AK, Curtis JR, Saag KG: The epidemiology of glucocorticoidassociated adverse events. Curr Opin Rheumatol 2008, 20:131-137.

doi:10.1186/1476-9255-7-53

Cite this article as: Scull et al: Macrophage pro-inflammatory cytokine secretion is enhanced following interaction with autologous platelets. Journal of Inflammation 2010 7:53.

\section{Submit your next manuscript to BioMed Central and take full advantage of:}

- Convenient online submission

- Thorough peer review

- No space constraints or color figure charges

- Immediate publication on acceptance

- Inclusion in PubMed, CAS, Scopus and Google Scholar

- Research which is freely available for redistribution
Biomed Central 